\title{
Patient-reported dermatomyositis and polymyositis flare symptoms are associated with disability, productivity loss, and health care resource use
}

Lisa Christopher-Stine, MD, MPH; George J Wan, PhD; William Kelly, MS; Mary McGowan, MA; Ryan Bostic, BS; and Michael L Reed, PhD

\section{What is already known about this subject}

- Dermatomyositis (DM) and polymyositis (PM) have long-term effects on a patient's quality of life and daily functioning.

- DM and PM may cause flare activity separated by periods of mild or no disease activity.

- Increasing flare frequency in inflammatory conditions may be indicative of worsening disease.

\section{What this study adds}

- This study emphasizes the effect of DM- and PM-related flare activity on patients' health, health care resource use, and productivity.

- Exacerbations of muscle weakness and fatigue are the most common flare symptoms contributing to greater disability and pain.

- Higher flare frequency is associated with greater health care resource use, work productivity loss, and nonwork activity impairment.

\author{
Author affiliations \\ Lisa Christopher-Stine, MD, MPH, and \\ William Kelly, MS, Johns Hopkins University, \\ Baltimore, MD. George J Wan, PhD, \\ Mallinckrodt Pharmaceuticals, Bedminster, \\ $\mathrm{NJ}$, and Mary McGowan, MA, The Myositis \\ Association, Alexandria, VA. Ryan Bostic, BS, \\ and Michael L Reed, PhD, Vedanta Research, \\ Chapel Hill, NC.
}

AUTHOR CORRESPONDENCE: Lisa Christopher-Stine, 410.550.6962; LChrist4@jhmi.edu

J Manag Care Spec Pharm 2020;26(11):1424-33

Copyright $\odot 2020$, Academy of Managed Care Pharmacy. All rights reserved.

myositis-related ED/UC visits, hospital admissions, WPAI work productivity loss (among those employed), and WPAI nonwork activity impairment.

CONCLUSIONS: DM/PM-related flares are common with exacerbations of muscle weakness and fatigue being the most common flare symptoms. Flare frequency was associated with greater disability, pain, work productivity loss, nonwork activity impairment, and increased ED/UC utilization. Higher frequency of patient-reported flares may serve as a marker of worsening physical functioning and intensifying health care needs and, therefore, suggests their importance in the clinical assessment of patients with DM/PM. 
Idiopathic inflammatory myopathies are a family of chronic, progressive autoimmune rare diseases, arising from a combination of genetic and environmental factors., ${ }^{1,2}$ There are several forms of idiopathic inflammatory myopathies, and while classification criteria are evolving, dermatomyositis (DM) and polymyositis (PM) are among the most recognizable subtypes. ${ }^{3}$ The global prevalence of DM and PM is estimated to be $2.0-10.0$ and 7.1 cases per 100,000 persons, respectively. ${ }^{4,5}$ The annual incidence rate of DM and PM is estimated to be 1.0-10.0 and 4.0-7.7 per 1 million persons, respectively. ${ }^{4,5}$ Among adults, DM and PM most commonly affect middle-aged females aged $40-60$ years; DM also affects children aged $5-15$ years. ${ }^{6,7}$

DM and PM are characterized by proximal skeletal muscle weakness and muscle inflammation. The muscle weakness affects muscles closest to the trunk, including hips, thighs, shoulders, upper arms, and neck. ${ }^{1,2}$ In addition, DM also exhibits skin manifestations, such as skin rash or skin ulceration. ${ }^{3}$ Muscle weakness is associated with increased morbidity and mortality rates. ${ }^{8}$ Individuals with DM or PM may experience difficulty in daily functioning, primarily climbing stairs, getting up from a seated position, or lifting items above their heads. ${ }^{7,9}$ Some people with these myopathies may also experience trouble breathing or swallowing.7 Further, these myopathies may be associated with other connective tissue disorders (scleroderma, systemic lupus erythematosus, and rheumatoid arthritis); cardiovascular diseases; lung disease; and cancer. ${ }^{10-12}$

Individuals with DM or PM have significantly higher health care resource utilization, including $44 \%$ more inpatient admissions and increased specialist visits (rheumatologists, neurologists, and physical therapists) compared with the general population. ${ }^{13}$ Further, people with these myopathies have substantially higher disease-related absenteeism, resulting in productivity loss and greater economic burden. ${ }^{13}$ Individuals with DM or PM also have 3 times higher mortality rate compared with the general population for chronic diseases. ${ }^{8}$

Although survival has gradually improved over recent decades, DM and PM continue to have long-term effects on quality of life and daily functioning. ${ }^{14} \mathrm{DM}$ and PM may cause flare activity separated by periods of mild or no disease activity. ${ }^{15}$ Flare activity generally manifests as increased muscle weakness and higher creatine levels, accompanied by fever and worsening of skin rash in the case of DM. ${ }^{3,15}$ Studies on inflammatory conditions suggest that increasing flare frequency may be indicative of worsening disease, resulting in significant morbidity. ${ }^{8,16,17}$ There is a lack of evidence evaluating the effect of myopathy-related flare activity on an individual's daily functioning and work productivity.

Current research in idiopathic inflammatory myopathies emphasizes the clinical aspects of the disease, measured by physicians. ${ }^{18}$ Recent studies performed by the OMERACT Myositis Special Interest Group have invited patients to the conversation about the important measures to capture patient-reported outcome measures, thus, broadening the conversation about myositis beyond just the physician's perspective. ${ }^{19,20}$ Indeed, patients strongly rated pain as one of the most important attributes of the disease, while classic teaching suggests that myositis tends to be a painless weakness. ${ }^{19}$ Clinical manifestation and disease-related experience are unique to each individual. Understanding self-reported flare activity from an individual's perspective may add insight into the myopathy-related burden and may indicate important markers of disease control and health care resource use.

The objectives of this study were to characterize the frequency and pattern of DM and PM flare activity from the patient perspective and to assess the effect of flare frequency on myositis-related disability and pain, health care resource utilization (emergency department or urgent care visits and hospital admissions), work productivity loss, and nonwork activity impairment. In this study, we addressed these objectives through surveys of individuals with a selfreported diagnosis of DM or PM from 2 sample sources.

\section{Methods}

\section{ETHICS}

The Ethical and Independent Review Services (Independence, $\mathrm{MO}$ ) reviewed the study methods, consent form, and survey tool and granted an exemption from the requirements of federal regulation 45 CFR 46.101(b)(2) and certified the exemption status of the protocol (\#17067-01) on May 26, 2016. Informed consent was provided by each study volunteer before survey participation.

\section{RECRUITMENT AND INCLUSION CRITERIA}

Respondents to the online survey were recruited from 2 source populations: The Myositis Association (TMA), a myositis patient advocacy group that serves caregivers and family members, and the Johns Hopkins Myositis Center (JHMC), a tertiary myositis clinic located in Baltimore, MD. All U.S. patient members (international email addresses were excluded) of TMA with a working email address $(n=5,542)$ were invited to participate in the survey from July 2017 to November 2017. Respondents recruited from JHMC were offered the opportunity to participate in the study during a clinic visit. Those who volunteered $(n=177)$ and who 
had not previously participated through TMA, were sent the same email invitation provided to TMA patient members. Data collection with JHMC occurred between December 2017 and May 2018. Email invitations were sent from the research organization (Vedanta Research) and included a secure, single-use link to the online data collection platform.

Study volunteers were presented with study information, provided informed consent, and completed a short health history question that asked, "Are you currently diagnosed with any of the following?" Response options included PM; necrotizing autoimmune myopathy (NAM); inclusion-body myositis (IBM); DM; myositis that occurs with other systemic diseases (e.g., mixed connective tissue disease, lupus, or scleroderma); and none of these. Respondents aged $\geq 18$ years who confirmed a diagnosis of DM, PM (including NAM and myositis with other systemic diseases), or IBM were offered the opportunity to complete a longer assessment. Volunteers who did not qualify were acknowledged for their interest in the study and the survey was discontinued.

Respondents from both populations who completed the survey received a one-time $\$ 25$ Amazon gift card as a token of appreciation. Nonresponding individuals and those with partially completed surveys received up to 2 email reminders to improve completion rates.

The analysis was focused on the subset of respondents from TMA and JHMC with a self-reported physician diagnosis of DM or PM. Individuals with IBM were analyzed separately and will be included in a separate paper.

\section{ASSESSMENTS}

Sociodemographic data, including gender, age, race, household income, employment status, and marital status, were assessed for each respondent. As an indicator of oral health status, ${ }^{21-23}$ tooth loss among respondents aged under 65 years was assessed by asking respondents, "Have you lost any teeth?" and "If so, how many teeth have you lost? (Do not count wisdom tooth extractions, root canals, or cracked teeth)." Myositis medication use was assessed by asking respondents to indicate on a pre-coded list "Which prescription medications are you currently using to treat or manage your myositis?" Medications were grouped into steroid and nonsteroid classes for the analysis.

To assess body mass index (BMI), respondents were asked to provide height and current weight, and BMI was calculated by dividing weight in pounds by height in inches squared and multiplying by a conversion factor of 703 . The duration of illness was assessed from the respondent's age at first diagnosis of myositis. Flare frequency was obtained by asking, "How many times have you had a flare or a worsening of your myositis symptoms in the past 12 months," and response options included "None in the past 12 months,"
"1 to 3 times," "4 to 6 times," "7 to 9 times," "10 or more flares," and "Don't remember/Don't know." Respondents with 4 or more flares were grouped, and those who did not remember or did not know were excluded from the analyses.

A list of potential myositis flare symptoms was developed from discussions with clinical experts (Christopher-Stein) and cognitive debriefing interviews with patients (Reed) conducted during instrument development. Myositis flare symptom patterns were obtained by asking respondents a yes-no question on the experience of flare activity from a pre-coded list: "Which of the following symptoms did you experience when you had a flare or your myositis worsened?" The symptoms comprised muscle weakness, difficulty reaching overhead, trouble climbing stairs, trouble standing from a seated position, pain or discomfort as muscles weaken, frequent falling episodes, difficulty getting up from a fall, extreme fatigue, dysphagia, breathing problems, skin rash or ulcers, gastric ulcers, and other new or unexplained problems. For this last category, respondents could enter additional flare activity symptoms.

The Health Assessment Questionnaire Disability Index (HAQ-DI) was included in the survey to help understand patient disability. ${ }^{24}$ This questionnaire is a patient-reported measure in which respondents report difficulty in the following 8 activity types: dressing/grooming, arising, eating, walking, hygiene, reach, grip, and common daily activities. Respondents rate their difficulty with each activity type from 0 (no difficulty) to 3 (unable to do). The response for each activity type was then summed and divided by 8 to compute a disability score. The HAQ also assesses a respondent's pain using a $0-100$ pain scale that is linearly transformed into a 0 (no pain) to 3 (worst pain ever) score.

Health care resource use was assessed by asking respondents, "How many times in the past 12 months did you visit an emergency room doctor or urgent care doctor for any reason?" and "How many times were you admitted to the hospital for any reason? A follow-up question for both types of provider encounter asked, "How many times were for the treatment of your myositis or related symptoms?" Emergency department (ED) and urgent care (UC) visits were combined for the analysis.

To understand work and activity-related impairment, the study used the Work Productivity and Activity ImpairmentGeneral Health (WPAI-GH) scale. ${ }^{25}$ This validated scale assesses work and nonwork activity-related impairment over the past week with 6 questions. These questions collect information on employment status, hours missed due to health problems, hours missed due to other reasons, hours actually worked, degree health affected productivity while working, and degree health affected nonwork activity. The scores include the percentage of work time missed due 
to health (absenteeism), percentage of impairment while working due to health (presenteeism), overall work impairment due to health (work productivity loss), and percentage of nonwork-related activity impairment. Absenteeism, presenteeism, and work productivity loss were estimated only among employed individuals. All respondents were included in the estimates of nonwork-related activity impairment.

\section{DATA INTEGRITY}

Before programming the survey instrument for online administration, clarity and content were reviewed in phone interviews (Reed) with myositis patients. The updated instrument was programmed for online administration and then pilot-tested with a small sample of respondents. After the data were collected, responses were subjected to a series of reliability and quality checks. Reliability was assessed by asking for a specific numerical response to a question, re-asking gender, birth month, and year at the end of the survey. Those with inconsistent responses were eliminated from the analysis. Additional quality checks included completion time parameters and an analysis of pattern-based responses. Average (SD) survey completion time was 39.6 (10.6) minutes, and respondents who completed the survey faster than 1.5 SDs from the mean completion time were excluded from the analyses. Respondents who straight-lined responses to survey questions (e.g., rated all items in a scale the same when this would be illogical or unlikely) were also excluded from the analyses. ${ }^{26}$

\section{STATISTICAL ANALYSIS}

Percentages were used to describe dichotomous and categorical variables, including gender, race, household income group, employment status, marital status, tooth loss, and medication use. Continuous variables included age, BMI, duration of illness, number of ED and/or UC visits, number of hospital admissions, disability, pain, and activity impairment and were described using mean and SDs. Because this analysis aimed to recognize and understand the effects of myositis flare frequency, the sample was stratified into flare frequency groups: never had a flare, 0 flares in the past 12 months, $1-3$ flares in the past 12 months, and $\geq 4$ flares in the past 12 months. Chi-square tests were used to evaluate differences between flare groups for dichotomous or categorical variables, and ANOVA was used to evaluate differences for continuous variables.

All statistical analyses were conducted at a priori significance level of 0.05. Analyses were performed using IBM SPSS Statistics, version 24.0 (IBM, Armonk, NY).

\section{Results}

\section{SAMPLING}

Completed surveys from TMA $(\mathrm{n}=750$, response rate $=13.5 \%)$ and JHMC $(\mathrm{n}=149$, response rate $=84.2 \%)$ totaled 899. After checks for internal consistency and other quality control measures were implemented, the final sample consisted of 876 respondents. Of these respondents, $83.0 \%(n=727)$ were from TMA and $17.0 \%(n=149)$ were from JHMC. The 2 samples were compared on demographic characteristics (Supplementary Table 1, available in online article) and were similar except for age, whereas the TMA sample was older (56 vs. 51 years, $P=0.001$ ), had a longer duration of illness ( 8.6 vs. 5.0 years, $\mathrm{P}<0.001)$, and were less likely to be employed $(41.2 \%$ vs. $52.9 \%, P=0.044)$. Medication use patterns also differed, with the JHMC sample reporting more nonsteroid medication-only use $(56.3 \%$ vs. $32.7 \%, \mathrm{P}<0.001)$. Supplementary Table 2 (available in online article) compared the TMA and JHMC samples on symptom frequency and no differences were observed. Supplementary Table 3 (available in online article) compares the TMA and JHMC sample on outcome measures, and TMA respondents reported more HAQ disability $(P<0.05)$, but no differences were observed for the other measures. The subsample of respondents with a selfreported physician diagnosis of DM $(n=321)$ or PM $(n=243)$ totaled 564, and 524 respondents recalled previous flare activity. Approximately $25 \%$ of the respondents $(n=215)$ were employed and provided data on work productivity loss. Respondents with a self-reported physician diagnosis of inclusion body myositis $(n=312)$ were excluded from this analysis.

\section{SOCIODEMOGRAPHIC CHARACTERISTICS}

Of the total DM/PM sample $(\mathrm{N}=524), 33(6.3 \%)$ reported never having a flare; $113(21.6 \%)$ reported a previous flare but none in the past 12 months; 244 (46.6\%) reported 1-3 flares in the past 12 months; and $134(25.6 \%)$ reported $\geq 4$ flares in the past 12 months. The total DM/PM sample had a mean age of 55 years; $78.1 \%$ were women; $86.6 \%$ were Caucasian; and $69.4 \%$ were married. The employment rate of the sample was $43.1 \%$, and over one third of the respondents reported a household income of more than $\$ 100,000$ per year. Of the 389 ( $74.2 \%)$ respondents under 65 years of age, $20.8 \%$ reported lost teeth; losing teeth also trended higher as flare frequency increased $(P=0.002)$. Medication use consisted of $6.7 \%$ of the sample reporting using only steroids to treat myositis, $36.6 \%$ using nonsteroid myositis medication, $43.1 \%$ using both steroid and nonsteroid medication to treat myositis, and $13.5 \%$ using no myositis-specific medication. A significant difference in rates of myositis medication use was found between flare groups $(\mathrm{P}<0.001)$. BMI trended higher as flare frequency increased $(P<0.043)$, with a mean 


\section{TABLE 1 Sociodemographic Characteristics of the Sample Stratified by Flare Frequency as Reported by Study Respondents}

\begin{tabular}{|c|c|c|c|c|c|c|c|c|c|c|c|c|}
\hline \multirow[b]{2}{*}{ Overall, N (\%) } & \multicolumn{2}{|c|}{$\begin{array}{l}\text { Never Had } \\
\text { a Flare }\end{array}$} & \multicolumn{2}{|c|}{$\begin{array}{l}0 \text { Flares in Past } \\
12 \text { Months }\end{array}$} & \multicolumn{2}{|c|}{$\begin{array}{c}\text { 1-3 Flares in Past } \\
12 \text { Months }\end{array}$} & \multicolumn{2}{|c|}{$\begin{array}{c}\geq 4 \text { Flares in Past } \\
12 \text { Months }\end{array}$} & \multicolumn{2}{|c|}{ Total } & \multirow[t]{2}{*}{$X^{2} / F$} & \multirow[t]{2}{*}{ P Value } \\
\hline & 33 & (6.3) & 113 & $(21.6)$ & 244 & $(46.6)$ & 134 & $(25.6)$ & 524 & $(100.0)$ & & \\
\hline \multicolumn{13}{|l|}{ Gender, n (\%) } \\
\hline Male & 12 & $(36.4)$ & 19 & $(16.8)$ & 53 & $(21.7)$ & 31 & $(23.1)$ & 115 & $(21.9)$ & 5.859 & 0.119 \\
\hline Female & 21 & $(63.6)$ & 94 & $(83.2)$ & 191 & $(78.3)$ & 103 & (76.9) & 409 & $(78.1)$ & & \\
\hline \multicolumn{13}{|l|}{ Race, n (\%) } \\
\hline Caucasian & 29 & $(87.9)$ & 96 & $(87.3)$ & 204 & $(86.8)$ & 112 & $(85.5)$ & 441 & $(86.6)$ & 1.358 & 0.968 \\
\hline African American & 4 & $(12.1)$ & 11 & $(10.0)$ & 26 & $(11.1)$ & 15 & $(11.5)$ & 56 & $(11.0)$ & & \\
\hline Other & 0 & $(0.0)$ & 3 & $(2.7)$ & 5 & (2.1) & 4 & (3.1) & 12 & $(2.4)$ & & \\
\hline \multicolumn{13}{|c|}{ Annual household income, $n$ (\%) } \\
\hline less than $\$ 24,999$ & 4 & $(13.3)$ & 10 & $(9.9)$ & 30 & $(14.6)$ & 26 & $(21.5)$ & 70 & $(15.3)$ & 16.674 & 0.162 \\
\hline$\$ 25,000-\$ 49,999$ & 2 & $(6.7)$ & 18 & $(17.8)$ & 33 & $(16.0)$ & 20 & $(16.5)$ & 73 & $(15.9)$ & & \\
\hline$\$ 50,000-\$ 74,999$ & 3 & $(10.0)$ & 20 & $(19.8)$ & 40 & $(19.4)$ & 21 & $(17.4)$ & 84 & $(18.3)$ & & \\
\hline$\$ 75,000-\$ 99,999$ & 5 & $(16.7)$ & 10 & $(9.9)$ & 33 & $(16.0)$ & 20 & $(16.5)$ & 68 & $(14.8)$ & & \\
\hline$\$ 100,000$ or more & 16 & $(53.3)$ & 43 & $(42.6)$ & 70 & $(34.0)$ & 34 & $(28.1)$ & 163 & $(35.6)$ & & \\
\hline \multicolumn{13}{|l|}{ Employment status, $\mathrm{n}(\%)$} \\
\hline Employed & 11 & $(33.3)$ & 53 & $(46.9)$ & 112 & $(45.9)$ & 50 & $(37.3)$ & 226 & $(43.1)$ & 4.559 & 0.207 \\
\hline \multicolumn{13}{|l|}{ Marital status, $\mathrm{n}(\%)$} \\
\hline Married & 24 & $(72.7)$ & 76 & $(67.9)$ & 172 & $(72.0)$ & 87 & $(65.4)$ & 359 & $(69.4)$ & 2.035 & 0.565 \\
\hline \multicolumn{13}{|l|}{ Tooth loss, n (\%) } \\
\hline $\begin{array}{l}\text { Under age } 65 \text {, tooth loss } \\
(n=389)\end{array}$ & 0 & $(0.0)$ & 13 & $(16.9)$ & 35 & $(18.5)$ & 33 & $(32.4)$ & 81 & $(20.8)$ & 15.081 & 0.002 \\
\hline \multicolumn{13}{|l|}{ Myositis medication use, $\mathrm{n}(\%)$} \\
\hline Steroids only & 3 & $(9.1)$ & 2 & $(1.8)$ & 21 & $(8.6)$ & 9 & $(6.7)$ & 35 & $(6.7)$ & 43.514 & $<0.001$ \\
\hline Nonsteroid meds only & 9 & $(27.3)$ & 45 & $(39.8)$ & 86 & $(35.2)$ & 52 & $(38.8)$ & 192 & $(36.6)$ & & \\
\hline Steroids plus nonsteroids & 13 & $(39.4)$ & 34 & $(30.1)$ & 120 & $(49.2)$ & 59 & $(44.0)$ & 226 & $(43.1)$ & & \\
\hline No myositis medication & 8 & $(24.2)$ & 32 & $(28.3)$ & 17 & $(7.0)$ & 14 & $(10.4)$ & 71 & $(13.5)$ & & \\
\hline \multicolumn{13}{|l|}{ Mean (SD) } \\
\hline Age (years) & 59.18 & $(11.75)$ & 56.32 & $(13.13)$ & 54.62 & $(12.68)$ & 54.96 & $(13.44)$ & 55.36 & $(12.94)$ & $\mathrm{F}=1.477$ & 0.220 \\
\hline BMI $\left(\mathrm{kg} / \mathrm{m}^{2}\right)$ & 27.59 & $(5.62)$ & 28.36 & $(6.97)$ & 29.7 & $(7.67)$ & 30.61 & $(7.38)$ & 29.51 & $(7.37)$ & $F=2.733$ & 0.043 \\
\hline Duration of illness (years) & 5.82 & $(5.01)$ & 10.89 & $(7.4)$ & 7.24 & $(6.34)$ & 7.36 & $(7.54)$ & 7.98 & $(6.99)$ & $F=9.204$ & $<0.001$ \\
\hline
\end{tabular}

BMI of $29.51 \mathrm{~kg} / \mathrm{m}^{2}$ for the total sample. The average duration of illness for the total sample was 8 years, and the mean duration of illness trended higher as flare frequency increased $(\mathrm{P}<0.001$; Table 1).

\section{SYMPTOMS}

Of the total DM/PM sample ( $\mathrm{N}=524), 73.3 \%$ (381) of respondents recalled having flares in the past year and were asked to recall flare symptoms. Flare frequency reports were similar between DM and PM subsamples except for skin rash, which was more common in DM, and muscle weakness, trouble climbing stairs, and falling and difficulty getting up, which were more common in PM (Supplemental Table 4, available in online article). In in the combined sample, the most common symptoms were muscle weakness (83\%), extreme fatigue (78\%), muscle pain/discomfort as muscles 


\section{TABLE 2 Flare Symptoms Stratified by Flare Frequency ${ }^{a}$}

\begin{tabular}{|c|c|c|c|c|c|c|}
\hline & $\begin{array}{l}0 \text { Flares in } \\
\text { Past } 12 \text { Months } \\
(n=6)\end{array}$ & $\begin{array}{l}\text { 1-3 Flares in } \\
\text { Past } 12 \text { Months } \\
(n=244)\end{array}$ & $\begin{array}{l}\geq 4 \text { Flares in } \\
\text { Past } 12 \text { Months } \\
(n=134)\end{array}$ & $\begin{array}{c}\text { Total } \\
(\mathrm{N}=\mathbf{3 8 1}) \\
\end{array}$ & $x^{2}$ & P Value \\
\hline Muscle weakness & $3(50.0)$ & $197 \quad(80.7)$ & $117 \quad(87.3)$ & $317 \quad(83.2)$ & 6.72 & 0.035 \\
\hline Difficulty reaching over my head & $2(33.3)$ & $94 \quad(39.0)$ & $51(38.1)$ & $147 \quad(38.6)$ & 0.103 & 0.950 \\
\hline Trouble climbing stairs & $4 \quad(66.7)$ & $137 \quad(56.8)$ & $94 \quad(70.1)$ & $235 \quad(61.7)$ & 6.512 & 0.039 \\
\hline Trouble standing from a seated position & $3(50.0)$ & 114 (47.3) & $73(54.5)$ & $190 \quad(49.9)$ & 1.773 & 0.412 \\
\hline Pain or discomfort as muscles weaken & $1(16.7)$ & $143 \quad(59.3)$ & 99 (73.9) & $243 \quad(63.8)$ & 13.743 & 0.001 \\
\hline Frequent falling episodes & $0 \quad(0.0)$ & $25(10.4)$ & $15(11.2)$ & $40 \quad(10.5)$ & 0.777 & 0.678 \\
\hline Falling and difficulty getting up from a fall & $0 \quad(0.0)$ & $43 \quad(17.8)$ & $29(21.6)$ & $72(18.9)$ & 2.232 & 0.328 \\
\hline Extreme fatigue or exhaustion & $4 \quad(66.7)$ & $178 \quad(73.9)$ & $116 \quad(86.6)$ & $298 \quad(78.2)$ & 8.64 & 0.013 \\
\hline Difficulty swallowing (dysphagia) & $2(33.3)$ & $58 \quad(24.1)$ & $42(31.3)$ & $102(26.8)$ & 2.46 & 0.292 \\
\hline Breathing or lung problems & $0 \quad(0.3)$ & $64(26.6)$ & $35 \quad(26.1)$ & $99 \quad(26.0)$ & 2.149 & 0.342 \\
\hline Skin rash or skin ulcers & $2(33.3)$ & $101 \quad(41.9)$ & $68 \quad(50.7)$ & $171(44.9)$ & 3.048 & 0.218 \\
\hline Gastric ulcers & $0 \quad(0.0)$ & $7 \quad(2.9)$ & $11 \quad(8.2)$ & $18 \quad(4.7)$ & 5.685 & 0.058 \\
\hline Other new or unexplained symptoms & $0 \quad(0.0)$ & $25 \quad(10.4)$ & $25 \quad(18.7)$ & $50 \quad(13.1)$ & 6.103 & 0.047 \\
\hline
\end{tabular}

Note: Results are shown as $n$ (\%).

aFlare symptoms were not assessed for respondents who reported "Never had a flare."

weaken (64\%), trouble climbing stairs (62\%), trouble standing from a seated position (50\%), and skin rash (45\%). Other new or unexplained symptoms totaled $13.1 \%$ and included nerve pain or discomfort and dizziness or balance issues. Flare symptoms that increased with flare frequency included muscle weakness $(P=0.035)$, trouble climbing stairs $(P=0.039)$, pain or discomfort as muscles weaken $(P=0.001)$, and extreme fatigue or exhaustion $(\mathrm{P}=0.013$; Table 2$)$.

\section{DISABILITY AND PAIN}

Disability was evaluated using the HAQ-DI (range: 0 no difficulty to 3 unable to do), and a significant trend toward greater disability was found as flare frequency increased $(P<0.001)$. Respondents who reported never having a flare had a mean (SD) HAQ-DI score of 0.51 (0.66), 0.79 (0.79) for those with no flares in the past 12 months, 1.06 (0.73) for the 1-3 flare group, and 1.34 (0.71) for the group reporting $\geq 4$ flares in the past 12 months. This same pattern was observed for pain as assessed by the HAQ pain scale (range $0=$ no pain to $3=$ worst ever pain) where reported pain increased as flare frequency increased $(P<0.001)$. The mean (SD) HAQ pain score was 0.45 (0.67) for the never had a flare group, 0.69 (0.83) for 0 flares in the past 12 months group,
1.02 (0.84) for the 1-3 flare group, and $1.52(0.78)$ for $\geq 4$ flares in the past 12 months group (Table 3 ).

\section{UNPLANNED HEALTH CARE PROVIDER USE}

Among the total DM/PM sample, 210 (40.1\%) respondents reported 1 or more ED/UC visit for any reason in the past year, and 94 (17.9\%) reported 1 or more visit specifically for myositis. The percentage with 1 or more ED/UC visit for any reason did not significantly differ by flare frequency group; however, increasing myositis-related visits were associated with increased flare frequency $(\mathrm{P}=0.009)$. Mean $(\mathrm{SD})$ past year myositis-related ED/UC visits ranged from $0.12(0.42)$ for the never flare group to 0.35 (1.09) for the $\geq 4$ flare group $(\mathrm{P}<0.01$; Table 3$)$.

One or more hospital admissions for any reason in the past year was reported by 116 (22.1\%) respondents, and $56(10.7 \%)$ reported 1 or more admission specifically for myositis. The percentage with 1 or more admission for any reason did not significantly differ by flare frequency group; however, increasing hospital-related visits were associated with increased flare frequency $(\mathrm{P}=0.029)$. Mean $(\mathrm{SD})$ past year myositis-related hospital admissions ranged from 0.09 (0.38) for the never flare group to 0.15 (0.47) for the $\geq 4$ flare group $(\mathrm{P}=0.007$; Table 3$)$. 


\section{TABLE 3 Outcomes Stratified by Flare Frequency}

\begin{tabular}{|c|c|c|c|c|c|c|c|}
\hline \multirow[b]{2}{*}{ Overall, n (\%) } & $\begin{array}{l}\text { Never Had a } \\
\text { Flare }\end{array}$ & $\begin{array}{l}0 \text { Flares } \\
\text { in Past } 12 \\
\text { Months }\end{array}$ & $\begin{array}{c}\text { 1-3 Flares } \\
\text { in Past } 12 \\
\text { Months }\end{array}$ & $\begin{array}{c}\geq 4 \text { Flares } \\
\text { in Past } 12 \\
\text { Months }\end{array}$ & \multirow{2}{*}{$\frac{\text { Total }}{524(100.0)}$} & \multirow[t]{2}{*}{$\mathbf{F}$} & \multirow[t]{2}{*}{$P$ Value } \\
\hline & (6.3) & $113 \quad(21.6)$ & $244 \quad(46.6)$ & $134 \quad(25.6)$ & & & \\
\hline \multicolumn{8}{|l|}{ HAQ scores } \\
\hline HAQ Disability Index, mean (SD) & $0.51 \quad(0.66)$ & $0.79 \quad(0.79)$ & $1.06 \quad(0.73)$ & $1.34 \quad(0.71)$ & $1.04 \quad(0.77)$ & 17.653 & $<0.001$ \\
\hline HAQ Pain Scale, mean (SD) & $0.45 \quad(0.67)$ & $0.69 \quad(0.83)$ & $1.02(0.84)$ & $1.52(0.78)$ & $1.04 \quad(0.87)$ & 28.291 & $<0.001$ \\
\hline \multicolumn{8}{|l|}{ ED/UC visits past year } \\
\hline One or more, any reason, $\mathrm{n}(\%)$ & $7 \quad(21.2)$ & $44 \quad(38.9)$ & $98 \quad(40.2)$ & $61 \quad(45.5)$ & $210 \quad(40.1)$ & $6.607^{b}$ & 0.086 \\
\hline Total visits, mean (SD) & $0.42 \quad(1.06)$ & $0.94 \quad(2.05)$ & $0.74 \quad(1.16)$ & $1.08 \quad(1.86)$ & $0.85 \quad(1.58)$ & 2.269 & 0.080 \\
\hline One or more, myositis related, n (\%) & $(9.1)$ & $10 \quad(8.8)$ & $50 \quad(20.5)$ & $31 \quad(23.1)$ & $94 \quad(17.9)$ & $11.634^{\mathrm{b}}$ & 0.009 \\
\hline Myositis-related visits, mean (SD) & $0.1 \quad(0.42)$ & $0.19 \quad(0.76)$ & $0.35 \quad(0.81)$ & $0.56 \quad(1.68)$ & 0.35 (1.09) & 3.054 & 0.028 \\
\hline \multicolumn{8}{|l|}{ Hospital admissions past year } \\
\hline One or more, any reason, $\mathrm{n}(\%)$ & $8 \quad(24.2)$ & $23 \quad(20.4)$ & $49 \quad(20.1)$ & $36 \quad(26.9)$ & $116 \quad(22.1)$ & $2.629^{b}$ & 0.452 \\
\hline Total admissions, mean (SD) & $0.39 \quad(0.86)$ & $0.31 \quad(0.71)$ & $0.26 \quad(0.60)$ & $0.46 \quad(0.89)$ & $0.33 \quad(0.73)$ & 2.163 & 0.091 \\
\hline One or more, myositis related, $\mathrm{n}(\%)$ & (6.1) & $(4.4)$ & $28 \quad(11.5)$ & $21 \quad(15.7)$ & $56 \quad(10.7)$ & $9.03^{b}$ & 0.029 \\
\hline Myositis-related admissions, mean (SD) & $0.09 \quad(0.38)$ & $0.05 \quad(0.26)$ & $0.14 \quad(0.43)$ & $0.25 \quad(0.65)$ & $0.15 \quad(0.47)$ & 4.050 & 0.007 \\
\hline \multicolumn{8}{|l|}{ WPAI scores, mean (SD) ${ }^{\mathrm{a}}$} \\
\hline $\begin{array}{l}\text { Percent of work time missed due to } \\
\text { health (absenteeism) }\end{array}$ & $0.63 \quad(1.98)$ & $4.78(15.88)$ & 8.95 (19.09) & $15.23(28.39)$ & $8.97(20.72)$ & 2.716 & 0.046 \\
\hline $\begin{array}{l}\text { Percent of time impaired while working } \\
\text { due to health (presenteeism) }\end{array}$ & $4 \quad(5.16)$ & 13.47 (23.5) & $23.58(21.74)$ & $32.5(22.84)$ & $22.15(23.07)$ & 8.242 & $<0.001$ \\
\hline $\begin{array}{l}\text { Percent overall work impairment due to } \\
\text { health (work productivity loss) }\end{array}$ & $4.56 \quad(6.11)$ & $16.28(27.88)$ & $28.75(26.81)$ & $42.15(29.16)$ & 27.65 & 9.933 & $<0.001$ \\
\hline Percent activity impairment (nonwork) & $17.58(26.22)$ & $29.2931 .36)$ & $41.64(28.56)$ & $52.01(26.97)$ & $40.11(30.19)$ & 20.109 & $<0.001$ \\
\hline
\end{tabular}

\section{WORK PRODUCTIVITY LOSS AND NONWORK ACTIVITY IMPAIRMENT}

Work productivity loss and nonwork activity impairment were assessed using the WPAI-GH, which provides an estimate of the percentage of past week work time missed (absenteeism) due to illness, time at work with lowered productivity (presenteeism), and an estimate of the percentage of missed nonwork activity time. Among the 215 employed respondents with WPAI data, there was an increasing trend associated with absenteeism and increasing flare frequency $(P=0.046)$. The mean percentage $(S D)$ of myositis-related absenteeism during the past week for the total sample was $8.97 \%$ of work time (20.72), increasing from $0.63 \%$ (1.98) for respondents who never had a myositis flare to $15.23 \%$ (28.39) for those with $\geq 4$ flares (Table 3 ). The pattern for presenteeism was similar. The mean (SD) percentage of presenteeism for the total employed sample was $22.15 \%$ of work time (23.07) and a significant trend of increased rates of presenteeism with increased flare frequency was found $(P<0.001)$. For respondents who never had a myositis flare, presenteeism averaged $4.0 \%$ (5.16), while those with 0 flares in the past year reported $13.47 \%$ (23.5); respondents with 1-3 flares reported $23.58 \%$ (21.74); and those with $\geq 4$ flares reported $32.5 \%$ (22.84; Table 3).

Work productivity loss was calculated for the combined effects of absenteeism and presenteeism. There was an increasing trend associated with mean work productivity loss and increasing flare frequency $(\mathrm{P}<0.001)$. The mean (SD) percentage of work productivity loss due to myositis for the total employed sample was $27.65 \%$ of work time (28.70), increasing from $4.56 \%$ (6.11) for respondents who 
never had a myositis flare to $42.15 \%$ (29.16) for those with $\geq 4$ flares (Table 3 ).

Among the total sample (employed and nonemployed respondents) the mean (SD) percentage of nonwork activity impairment was $40.11 \%$ of the nonwork time (30.19), and a significant trend of greater nonwork activity impairment with increased flare frequency was found $(F=20.109$, $\mathrm{P}<0.001)$. Respondents who never had a myositis flare reported that $17.58 \%$ (26.22) of their past week nonwork activity was impaired due to myositis, while those with 0 flares in the past year reported 29.29\% (31.36); those with 1-3 flares reported $41.64 \%$ (28.56); and those with $\geq 4$ flares reported $52.01 \%$ (26.97; Table 3$)$.

\section{Discussion}

The aim of this study was to understand the burden of DMand PM-related flare activity from the patient perspective. DM- and PM-related flares or worsening symptoms were common in this study sample- $72 \%$ of the total respondents reported at least 1 flare during the past 12 months. The pattern of flare frequency was similar for DM and PM respondents. Most of the respondents reported exacerbations of muscle weakness, fatigue, pain or discomfort, and trouble climbing stairs as the common flare symptoms. These symptoms were significantly more common among those with $\geq 4$ flares in the past 12 months. Over two thirds of the respondents with DM also experienced exacerbations of skin rashes or skin ulcers. Increasing flare frequency was significantly associated with greater disability and pain, health care resource utilization, work productivity loss, and nonwork activity impairment.

To our knowledge, this is the first study to understand the effect of DM- and PM-related flare activity on respondents' health, health care resource use, and productivity. DM and PM are rare diseases, making it difficult to conduct a study with an adequate sample size. This is one of the largest survey research studies to evaluate the burden of DM- and PM-related flare activity and quantify the increased need for patient-centered care. Findings from this study add to the nascent literature on the humanistic burden of DM and PM from a patient perspective. These findings are essential for generating new hypotheses.

Higher frequency of patient-reported flares may serve as a marker of worsening physical functioning and intensifying health care needs and suggests the importance of patient reports in the clinical assessment of DM and PM. The findings from this study indicate that respondents with higher flare frequency were more likely to report muscle weakness-related symptoms, disability, pain, and activity impairment. A decline in physical functioning can hinder social and role functioning; higher flare frequency was found to be significantly associated with greater work productivity loss among employed respondents. In addition to financial loss, patients facing time off work because of flare activity may also be affected socially and emotionally. ${ }^{27,28}$ Together, these data highlight the importance of understanding such interfering influences and warrants patient support to improve their physical functioning and overall well-being.

Further, DM and PM may result in increased health care utilization and incur subsequent indirect costs. Eighteen percent of the respondents had 1 or more myositis-related ED and UC visits, and this increased from 9.1\% among the never flare group to $23.1 \%$ for the $\geq 4$ flare group. A similar pattern was seen for myositis-related hospital admissions, where $10.7 \%$ reported 1 or more in the past year, which increased from $6.1 \%$ for the never group to $17.7 \%$ for the $\geq 4$ flare group. While there is no published literature on the relationship between myositis flare activity and health care resource utilization, previous research on DM and $\mathrm{PM}_{1}^{13}$ idiopathic inflammatory myopathies, ${ }^{29}$ and other chronic musculoskeletal diseases ${ }^{30,31}$ suggest that these inflammatory conditions contribute to greater health care resource utilization and economic burden.

\section{LIMITATIONS}

We recognize the limitations of this study. Our dataset did not include individuals with undiagnosed DM or PM, and diagnosis of myositis was self-reported and not verified by a physician. However, all patients in the JHMC cohort had been evaluated by a physician, and TMA provides education to myositis patients who have been frequently referred to the organization by their treating physician who has diagnosed them.

We also recognize that flare activity was determined by the patients and not independently verified by a physician. Our analysis was limited to a descriptive summary of trends, without controlling for or modeling the potential role of sociodemographic characteristics or other variables in assessing the burden associated with increasing flare frequency. Because there was no validated definition of flare agreed upon by expert consensus, and frequently inflammatory markers such as erythrocyte sedimentation rate and C-reactive protein are normal even with significant inflammation, ${ }^{32}$ the acquisition of patient self-reported flare provides valuable clinical information.

In addition, creatine kinase may be normal in dermatomyositis even when the disease is not strictly amyopathic (or with subclinical muscle weakness). ${ }^{33}$ Thus, relying on patient report of symptoms can be important. Indeed, the self-reported patient global assessment is one of the key 
measures in the comprehensive evaluation of myositis. ${ }^{19}$

Finally, it is impractical to have every suspected flare episode verified independently by a physician's assessment and examination. We also note that while this study found a substantial number of respondents with flare activity, the populationbased survey may not have captured the most severe cases.

The study findings may not be generalizable to all DM and PM populations. The participants were selected from TMA and JHMC; military personnel, hospitalized patients, and individuals from upper and lower socioeconomic status classes may be underrepresented in the survey sample. Additionally, non-Englishspeaking populations were not included in the survey. The flare frequency, ED and UC visits, and burden were self-reported and may be subject to recall bias, which may result in underestimation of these estimates.

Despite the limitations, this study provides an initial paradigm from the patient's perspective for evaluating the association between flare activity and underlying myopathies.

\section{Conclusions}

The study findings indicate that selfreported flare activity may be an indicator of the burden of DM and PM, specifically within the realms of disability and pain, health care resource use, and lost productive work time and nonwork activity impairment. A better understanding of the burden of flare activity from a patient's perspective can help with appropriate management of DM and PM, resulting in improved patient quality of life and reduced economic burden. Further studies to correlate self-reported flares with physician assessments are needed.

\section{DISCLOSURES}

This study was supported by Mallinckrodt Pharmaceuticals (Bedminster, NJ) via grants to Vedanta Research and The Myositis Association. Christopher-Stine has received compensation from previous Mallinckrodt Advisory Board meetings, unrelated to this subject matter. Wan is an employee of Mallinckrodt Pharmaceuticals and is a stockholder of the company. Reed and Bostic received grant support from Mallinckrodt Pharmaceuticals for data collection and analysis. McGowan is an employee of The Myositis Foundation, which received grant funding to support study data collection. Kelly has no conflicts to disclose.

This study was presented, in part or full, at the 2019 Annual American College of Rheumatology and Association of Rheumatology Professional Meeting (November 8-13, 2018; Atlanta, GA) and at the Third Global Conference on Myositis (March 27, 2019; Berlin, Germany).

\section{ACKNOWLEDGMENTS}

Kristina Fanning of Vedanta Research provided analytical support and Ishveen Chopra of Manticore Consultancy provided medical writing support.

\section{REFERENCES}

1. Amato AA, Barohn RJ. Evaluation and treatment of inflammatory myopathies. J Neurol Neurosurg Psychiatry. 2009;80(10):1060-68.

2. Dalakas MC, Hohlfeld R. Polymyositis and dermatomyositis. Lancet. 2003;362(9388):971-82.

3. Malik A, Hayat G, Kalia JS, Guzman MA. Idiopathic inflammatory myopathies: clinical approach and management. Front Neurol. 2016;7:64

4. Orphanet. Polymyositis. 2014. Accessed September 17, 2020. https://www. orpha.net/consor/cgi-bin/OC_Exp. php?Expert $=732$

5. Orphanet. Dermatomyositis. 2014. Accessed September 17, 2020. https:// www.orpha.net/consor/cgi-bin/OC Exp. php?Expert $=221$

6. Cheeti A, Panginikkod S. Dermatomyositis and Polymyositis. StatPearls Publishing; 2019.
7. National Institutes of Health. Idiopathic inflammatory myopathy. 2019. Accessed September 17, 2020. https://ghr.nlm.nih. gov/condition/idiopathic-inflammatorymyopathy\#

8. Marie I. Morbidity and mortality in adult polymyositis and dermatomyositis. Curr Rheumatol Rep. 2012;14(3):275-85.

9. Poulsen KB, Alexanderson H, Dalgard C, Jacobsen S, Weile L, Diederichsen LP. Quality of life correlates with muscle strength in patients with dermato- or polymyositis. Clin Rheumatol. 2017;36(10):2289-95.

10. Hak AE, de Paepe B, de Bleecker JL, Tak PP, de Visser M. Dermatomyositis and polymyositis: new treatment targets on the horizon. Neth J Med. 2011;69(10):410-21.

11. Tisseverasinghe A, Bernatsky S, Pineau CA. Arterial events in persons with dermatomyositis and polymyositis.

J Rheumatol. 2009;36(9):1943-46.

12. Marie I, Hachulla E, Cherin P, et al. Interstitial lung disease in polymyositis and dermatomyositis. Arthritis Rheum. 2002;47(6):614-22.

13. Bradford Rice J, White A, Lopez A, et al Healthcare resource utilization and work loss in dermatomyositis and polymyositis patients in a privately-insured U.S. population. J Med Econ. 2016;19(7):649-54.

14. Ponyi A, Borgulya G, Constantin T, Vancsa A, Gergely L, Danko K. Functional outcome and quality of life in adult patients with idiopathic inflammatory myositis. Rheumatology (Oxford). 2005;44(1):83-88.

15. Mammen AL. Dermatomyositis and polymyositis: clinical presentation, autoantibodies, and pathogenesis. Ann N Y Acad Sci. 2010;1184:134-53.

16. Markusse IM, Dirven L, Gerards AH, et al. Disease flares in rheumatoid arthritis are associated with joint damage progression and disability: 10-year results from the BeSt study. Arthritis Res Ther. 2015;17:232.

17. Sprangers B, Monahan M, Appel GB. Diagnosis and treatment of lupus nephritis flares-an update. Nat Rev Nephrol. 2012;8(12):709-17. 
18. Park JK, Mecoli CA, Alexanderson H, et al. Advancing the development of patient-reported outcomes for adult myositis at OMERACT 2016: an international Delphi study. J Rheumatol. 2017;44(11):1683-87.

19. Park JK, Mecoli CA, Alexanderson $\mathrm{H}$, et al. Advancing the development of patient-reported outcomes for adult myositis at OMERACT 2016: an international Delphi study. J Rheumatol. 2018;45(7):1071.

20. Zamora NV, Christensen R, Goel N, et al. Critical outcomes in longitudinal observational studies and registries in patients with rheumatoid arthritis: an OMERACT Special Interest Group Report. J Rheumatol. 2017;44(12):1894-98.

21. Gualtierotti R, Marzano AV, Spadari F, Cugno M. Main oral manifestations in immune-mediated and inflammatory rheumatic diseases. J Clin Med. 2018;8(1):21.

22. Tanaka TI, Geist SM. Dermatomyositis: a contemporary review for oral health care providers. Oral Surg Oral Med Oral Pathol Oral Radiol. 2012;114(5):e1-8.

23. Marton K, Hermann P, Danko K, Fejerdy P, Madlena M, Nagy G. Evaluation of oral manifestations and masticatory force in patients with polymyositis and dermatomyositis. J Oral Pathol Med. 2005;34(3):164-69.
24. Fries JF, Spitz P, Kraines RG, Holman HR. Measurement of patient outcome in arthritis. Arthritis Rheum. 1980;23(2):137-45.

25. Reilly MC, Zbrozek AS, Dukes EM. The validity and reproducibility of a work productivity and activity impairment instrument. Pharmacoeconomics. 1993;4(5):353-65.

26. Kim Y, Dykema J, Stevenson J, Black P, Moberg DP. Straightlining: overview of measurement, comparison of indicators, and effects in mail-web mixed-mode surveys. Soc Sci Comput Rev. 2019;37(2):21433. doi: 10.1177/0894439317752406

27. Beaton D. SP0110 How to use work productivity as an outcome measure in clinical settings. Ann Rheum Dis. 2015;74:28. doi: 10.1136/annrheumdis2015-eular.6649

28. Regardt M, Welin Henriksson E, Sandqvist J, Lundberg IE, Schult ML. Work ability in patients with polymyositis and dermatomyositis: an explorative and descriptive study. Work. 2015;53(2):265-77.

29. Furst DE, Amato AA, Iorga SR, Bancroft T, Fernandes AW. Medical costs and health-care resource use in patients with inflammatory myopathies in an insured population. Muscle Nerve. 2012;46(4):496-505.
30. United States Bone and Joint Initiative. The Burden of Musculoskeletal Diseases in the United States: Prevalence, Societal and Economic Cost. 4th ed. United States Bone and Joint Initiative; 2020.

31. Merkesdal S, Ruof J, Huelsemann JL, et al. Indirect cost assessment in patients with rheumatoid arthritis (RA): comparison of data from the health economic patient questionnaire HEQ-RA and insurance claims data. Arthritis Rheum. 2005;53(2):234-40.

32. Watson J, Jones HE, Banks J, Whiting P, Salisbury C, Hamilton W. Use of multiple inflammatory marker tests in primary care: using Clinical Practice Research Datalink to evaluate accuracy. $\mathrm{Br} \mathrm{J}$ Gen Pract. 2019;69(684):e462-e469.

33. Koler RA, Montemarano A. Dermatomyositis. Am Fam Physician. 2001;64(9):1565-72. 